\title{
Polymerization of Polar Vinyl Monomers by Cobalt Complex-Alkylaluminum Compound
}

\author{
Kenji Tsuchihara, ${ }^{\dagger}$ Yasuzo SuZukI, Michihiko AsaI, and Kazuo SogA* \\ Department of Polymer Chemistry, National Institute of Materials and Chemical Research, \\ 1-1 Higashi, Tsukuba 305-8565, Japan \\ *School of Materials Science, Japan Advanced Institute of Science and Technology, \\ 15 Asahidai, Tatsunokuchi, Ishikawa 923-1292, Japan
}

(Received August 23, 1999)

\begin{abstract}
KEY WORDS Cobalt Complex / Alkylaluminum / Polymerization / Acrylonitrile / Methyl Methacrylate / Polar Vinyl Monomer /
\end{abstract}

The polymerization of polar vinyl monomers with transition-metal complex has been difficult because polar groups coordinate to the active site to prevent polymerization. Recently, several transition-metal complexes effective for the polymerization of polar vinyl monomers have been discovered, and for methyl methacrylate (MMA) living and stereospecific polymerizations have been conducted using early transition metal ${ }^{1}$ and rare earth metal complexes. ${ }^{2}$ Few examples of coordination polymerization have been reported for another polar monomers like acrylonitrile $(\mathrm{AN}),{ }^{3-7}$ and precision polymerization has not been achieved.

Olefin polymerization by catalyst systems which consist of transition-metal complex carrying cyclopentadienyl groups and alkylaluminum compound has been intensively studied. Very high catalytic activity and precision polymerization like living and stereospecific polymerization have been achieved using these catalyst systems. $^{8-10}$ Cyclopentadienyl groups and alkylaluminum compound are considered the key in these systems. However, the polymerization of polar vinyl monomers by such catalyst systems has rarely been studied. ${ }^{11}$

Recently, we reported that $\mathrm{CH}_{3} \mathrm{C}\left(\mathrm{CH}_{2} \mathrm{PPh}_{2}\right)_{3} \mathrm{Co}\left(\mathrm{BH}_{4}\right)$, which was a late transition metal complex having a tripod phosphine ligand, is effective for the polymerization of polar vinyl monomers without alkylaluminum compound. ${ }^{6}$ The complex, however, had no cyclopentadienyl group, and was unstable in air. The polymerization behavior of polar vinyl monomers should be studied by stable cobalt complex with cyclopentadienyl group activated by alkyl aluminum compound. This paper reports on the polymerization of polar vinyl monomers, especially AN, by such a type of catalyst system.

\section{EXPERIMENTAL}

\section{Materials}

AN, MMA, vinyl acetate, and styrene were washed with dilute $\mathrm{NaOH}$ and water, dried with $\mathrm{CaCl}_{2}$ or $4 \mathrm{~A}$ molecular sieves, and distilled twice under dry nitrogen just before use for polymerization. Ethylene and propyl-

\footnotetext{
${ }^{\dagger}$ To whom correspondence should be addressed.
}

ene were commercially obtained and purified with passing through columns with $\mathrm{KOH}$. Reagent grade solvents were dried with calcium hydride or $4 \mathrm{~A}$ molecular sieves and distilled under dry nitrogen. $\mathrm{Et}_{3} \mathrm{Al}$ and toluene solution of methylalumoxane (MAO) were purchased from Tosoh-akzo and used without further purification. Halfmetallocene type cobalt complex was synthesized according to the literature ${ }^{12,13}$ as follows. In dry nitrogen, equimolar amounts of $\mathrm{CpCo}(\mathrm{CO})_{2}$ and $\mathrm{I}_{2}$ were dissolved in dry THF followed by adding $\mathrm{PPh}_{3}$ in dry THF. After stirring for $24 \mathrm{~h}$ at room temperature, the precipitate was filtered, washed with toluene and hexane and dried in vacuo.

\section{Polymerization}

All polymerizations were carried out under dry nitrogen atmosphere using standard Schlenk tube technique. Standard polymerization conditions and procedures were as follows: in toluene at room temperature for $24 \mathrm{~h}$, $[$ monomer $]=7.5 \mathrm{M}$, [Co complex $]=7.5 \times 10^{-3} \mathrm{M}$, $[\mathrm{Al}$ compound $] /[$ Co complex $]=200$. In a $20 \mathrm{~mL}$ schlenk tube cobalt complex and monomer were dissolved in DMF followed by aging for $10 \mathrm{~min}$ at room temperature. A solution of alkylaluminum compound was added by syringe to start the polymerization. For ethylene and propylene polymerization, a $100 \mathrm{~mL}$ stainless steel reactor was used. After polymerization, the solution was poured into dilute $\mathrm{HCl}$ solution of methanol to remove the catalyst, filtered, and dried in vacuo. Polymer yield was determined by weighing the methanol insoluble product.

\footnotetext{
Measurements

${ }^{1} \mathrm{H}$ and ${ }^{13} \mathrm{C}$ NMR spectra of polymers were recorded at $25^{\circ} \mathrm{C}$ in $\mathrm{CDCl}_{3}$ or $N, N^{\prime \prime}$-dimethylformamide (DMF)- $d_{7}$ using a JEOL GX-270 spectrometer. Molecular weight and molecular weight distribution were determined by size exclusion chromatography (SEC) measured at $40^{\circ} \mathrm{C}$ by Tosoh 8020 liquid chromatograph system equipped with Tosoh $\alpha-\mathrm{M}$ and $\alpha-4000$ polystyrene gel columns. DMF (containing $10 \mathrm{mM} \mathrm{LiBr}$ ) was used as eluent, and a calibration curve was obtained by standard polystyrene samples.
} 
Table I. Polymerization by $\mathrm{CpCo}\left(\mathrm{PPh}_{3}\right) \mathrm{I}_{2}-\mathrm{Et}_{3} \mathrm{Al}^{\mathrm{a}}$

\begin{tabular}{lrccc}
\hline \multicolumn{1}{c}{ Monomer } & $e$-value & Polymer yield/\% & $M_{n}$ & $M_{w} / M_{n}$ \\
\hline Acrylonitrile & 1.20 & 38 & 5600 & 2.2 \\
Methyl methacrylate & 0.40 & 26 & 8400 & 2.0 \\
Ethylene & & 0 & - & - \\
Vinyl acetate & -0.20 & 0 & - & - \\
Propylene & -0.78 & 0 & - & - \\
Styrene & -0.80 & 0 & - & - \\
\hline
\end{tabular}

${ }^{\text {a }}$ Polymerized in toluene at room temperature for $24 \mathrm{~h}$, [Monomer $]=7.5 \mathrm{M},\left[\mathrm{CpCo}\left(\mathrm{PPh}_{3}\right) \mathrm{I}_{2}\right]=7.5 \mathrm{mM},\left[\mathrm{Et}_{3} \mathrm{Al}\right]=1.5 \mathrm{M}$.

Table II. Polymerization of $\mathrm{AN}$ by $\mathrm{CpCo}\left(\mathrm{PPh}_{3}\right) \mathrm{I}_{2}-\mathrm{Et}_{3} \mathrm{Al}^{\text {a }}$

\begin{tabular}{ccccc}
\hline \multirow{2}{*}{ [Al] $/[\mathrm{Co}]$} & Polymn time/h & \multicolumn{3}{c}{ Polymer } \\
\cline { 3 - 5 } & & Yield/\% & $M_{n}$ & $M_{w} / M_{n}$ \\
\hline 200 & 24 & 38 & 5600 & 2.2 \\
50 & 24 & 18 & 5800 & 2.1 \\
10 & 24 & 4 & 4800 & 2.6 \\
0 & 24 & 0 & - & - \\
200 & 8 & 33 & 5200 & 2.0 \\
200 & 4 & 25 & 5100 & 2.6 \\
200 & 1 & 14 & 4800 & 2.9 \\
$\mathrm{Et}_{3} \mathrm{Al}^{\text {b }}$ & 24 & 9 & 3800 & 2.8 \\
\hline
\end{tabular}

${ }^{a}$ Polymerized in toluene at room temperature for $24 \mathrm{~h},[\mathrm{AN}]=$ $7.5 \mathrm{M},\left[\mathrm{CpCo}\left(\mathrm{PPh}_{3}\right) \mathrm{I}_{2}\right]=7.5 \mathrm{mM}$. ${ }^{\mathrm{b}}$ Polymerized by $\mathrm{Et}_{3} \mathrm{Al}$ alone; $\left[\mathrm{Et}_{3} \mathrm{Al}\right]=1.5 \mathrm{M}$.

\section{RESULTS AND DISCUSSION}

Polymerizations of various vinyl monomers were examined using the $\mathrm{CpCo}\left(\mathrm{PPh}_{3}\right) \mathrm{I}_{2}-\mathrm{Et}_{3} \mathrm{Al}$ catalyst system. As shown in Table I, $\mathrm{CpCo}\left(\mathrm{PPh}_{3}\right) \mathrm{I}_{2}-\mathrm{Et}_{3} \mathrm{Al}$ polymerized polar vinyl monomers carrying electron-withdrawing group, which have large $e$-value, to give methanolinsoluble polymers in moderate yield. Methanol-soluble products included small amounts of linear oligomers. Molecular weight and molecular weight distribution of the polymers were several thousands and around 2 , respectively. SEC curves of the polymer were unimodal, indicating the active species of the polymerization should be homogeneous. Polymer yield of AN was higher than that of MMA, though polymer molecular weight was lower. No polymer was obtained from polar monomers having electron-donating group. The polymerization of olefins did not occur, though $\left[\mathrm{C}_{5} \mathrm{Me}_{5} \mathrm{P}(\mathrm{OMe})_{3}\right.$ $\left.\mathrm{CoCH}_{2} \mathrm{CH}-\mu-\mathrm{H}\right]^{+}$is said to cause the living polymerization of ethylene. ${ }^{14}$

Table II describes the polymerization of $\mathrm{AN}$ by $\mathrm{CpCo}\left(\mathrm{PPh}_{3}\right) \mathrm{I}_{2}-\mathrm{Et}_{3} \mathrm{Al}$. The complex polymerized $\mathrm{AN}$ only when $\mathrm{Et}_{3} \mathrm{Al}$ was added as activator, and no polymer was obtained with $\mathrm{CpCo}\left(\mathrm{PPh}_{3}\right) \mathrm{I}_{2}$ alone. The poly(AN) produced was soluble in DMF. Polymer yield, only $4 \%$ when $[\mathrm{Al}] /[\mathrm{Co}]$ was 10 , dramatically increased with this ratio, and was saturated around $40 \%$. $\mathrm{CpCo}\left(\mathrm{PPh}_{3}\right) \mathrm{Et}_{2}$, in which iodines of $\mathrm{CpCo}\left(\mathrm{PPh}_{3}\right) \mathrm{I}_{2}$ are alkylated, did not give poly-(AN) without $\mathrm{Et}_{3} \mathrm{Al}$. Thus, $\mathrm{Et}_{3} \mathrm{Al}$ acts not only as alkylating agent but also as modifier of monomer and/ or of active species. Polymer molecular weight and molecular weight distribution were almost identical during polymerization, indicating some transfer and/or termination reactions occur during polymerization. AN was polymerized by $\mathrm{Et}_{3} \mathrm{Al}$ alone, though polymerization activity was rather low.
Table III. Polymerization of MMA by $\mathrm{CpCo}\left(\mathrm{PPh}_{3}\right) \mathrm{I}_{2}{ }^{\mathrm{a}}$

\begin{tabular}{lrrcc}
\hline & & \multicolumn{3}{c}{ Polymer } \\
\cline { 3 - 5 } Al compound & {$[\mathrm{Al}] /[\mathrm{Co}]$} & Yield/\% & \multicolumn{1}{c}{$M_{n}$} & $M_{u} / M_{n}$ \\
\hline $\mathrm{Et}{ }_{3} \mathrm{Al}$ & 200 & 26 & 12000 & 2.4 \\
$\mathrm{Et}_{3} \mathrm{Al}$ & 20 & 5 & 9500 & 2.8 \\
$\mathrm{Et} 3 \mathrm{Al}$ & 0 & 0 & - & - \\
$\mathrm{MAO}$ & 200 & 11 & 5400 & 2.7 \\
$\mathrm{Et}_{3} \mathrm{Al}{ }^{\mathrm{b}}$ & $-{ }^{\mathrm{b}}$ & 0 & - & - \\
$\mathrm{MAO}^{\mathrm{b}}$ & $-{ }^{\mathrm{b}}$ & 0 & - & - \\
\hline
\end{tabular}

${ }^{\text {a }}$ Polymerized in toluene at room temperature for $24 \mathrm{~h}$, [MMA] $=7.5 \mathrm{M},\left[\mathrm{CpCo}\left(\mathrm{PPh}_{3}\right) \mathrm{I}_{2}\right]=7.5 \mathrm{mM} .{ }^{\mathrm{b}}$ Polymerized by aluminum compound alone; $[\mathrm{Al}]=1.5 \mathrm{M}$.

(a)

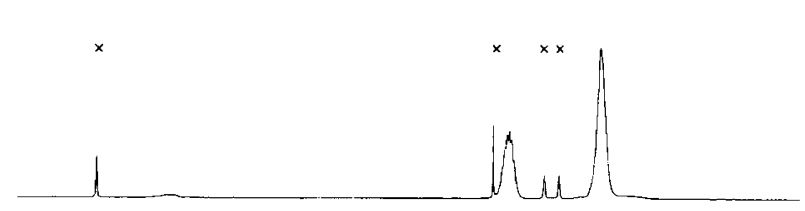

(b)

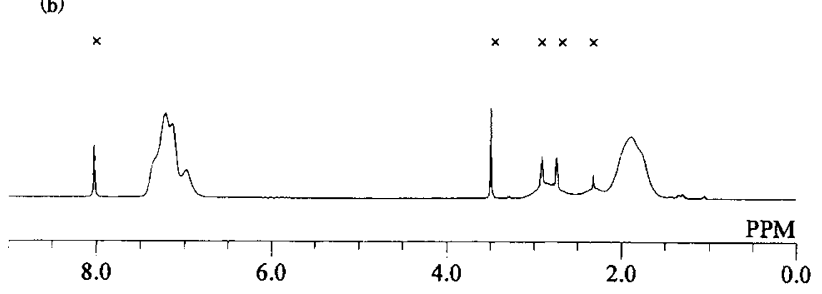

Figure 1. ${ }^{1} \mathrm{H}$ NMR spectra of the polymer obtained by copolymerization of $\mathrm{AN}$ and $\mathrm{St}$ with (a) $\mathrm{CpCo}\left(\mathrm{PPh}_{3}\right) \mathrm{I}_{2}-\mathrm{Et}_{3} \mathrm{Al}$ (b) $\mathrm{Et}_{3} \mathrm{Al}$ (measured in DMF- $d_{7}, \times$ : impurity).

Table III describes the polymerization of MMA by $\mathrm{CpCo}\left(\mathrm{PPh}_{3}\right) \mathrm{I}_{2}-\mathrm{Et}_{3} \mathrm{Al}$. The polymerization occurred only when alkylaluminum compound was added and $\mathrm{CpCo}$ $\left(\mathrm{PPh}_{3}\right) \mathrm{I}_{2}$ alone could not produce poly(MMA). The polymer was a white solid, and soluble in various organic solvents like toluene and $\mathrm{CHCl}_{3}$. Polymer yield was greatly dependent on $[\mathrm{Al}] /[\mathrm{Co}]$, and reached $26 \%$ when this ratio was 200 . The same was noted for $\mathrm{AN}$, though polymerization activity was lower than that of $\mathrm{AN}$. No polymer was obtained by $\mathrm{Et}_{3} \mathrm{Al}$ or MAO alone.

The living radical polymerization of polar vinyl monomers using transition metal complex is reported as atom-transfer radical polymerization. ${ }^{15}$ Thus, to make clear the polymerization mechanism, the copolymerization of AN with styrene (St) was attempted because copolymerization reactivity of radical copolymerization is hardly affected by polymerization conditions. As shown in Figure 1b, random copoly(AN-St) was obtained when equimolar amounts of $\mathrm{AN}$ and St were copolymerized by $\mathrm{Et}_{3} \mathrm{Al}$ alone (Polymerization conditions were similar to those for homopolymerization except for polymerization time of $30 \mathrm{~min}$ ). The composition curve of this copolymerization was similar to that of radical copolymerization. Thus, polymerization by $\mathrm{Et}_{3} \mathrm{Al}$ is considered to proceed by a radical polymerization mechanism. When $\mathrm{CpCo}-$ $\left(\mathrm{PPh}_{3}\right) \mathrm{I}_{2}-\mathrm{Et}_{3} \mathrm{Al}$ was used, the main product of the copolymerization was AN homopolymer, and only small aromatic peaks of styrene unit, probably derived from 


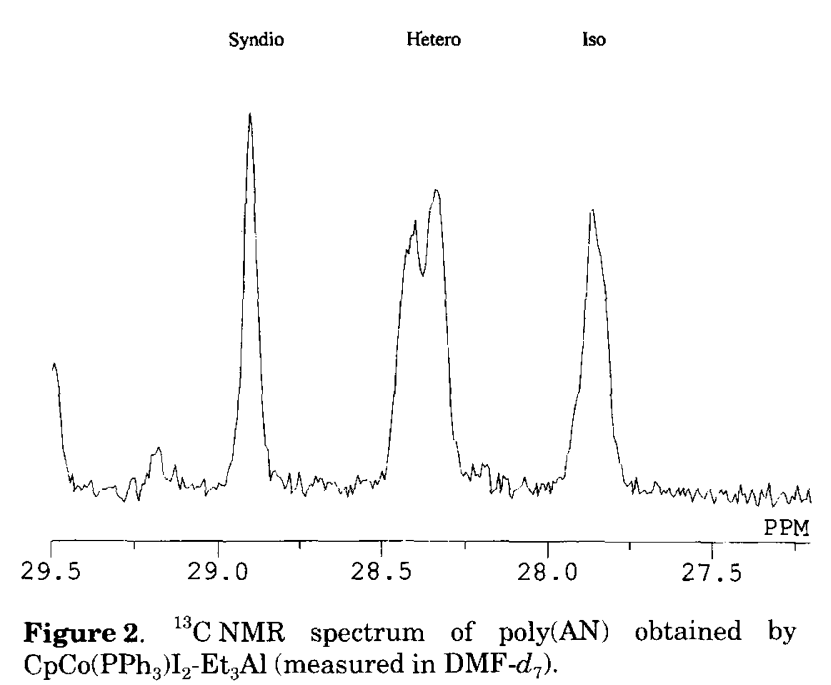

the copolymer formed by $\mathrm{Et}_{3} \mathrm{Al}$ alone, were observed in the ${ }^{1} \mathrm{H}$ NMR spectrum of the product (Figure 1a). This did not change even when [St]/[AN] increased, though polymerization activity greatly decreased. This was clearly different from the case of radical copolymerization. A radical polymerization inhibitor such as $2,2,6,6$ tetramethyl-1-piperidinyloxy radical (TEMPO) was essentially ineffective for the polymerization by $\mathrm{CpCo}$ $\left(\mathrm{PPh}_{3}\right) \mathrm{I}_{2}-\mathrm{Et}_{3} \mathrm{Al}$. Therefore, the polymerization by $\mathrm{CpCo}$ $\left(\mathrm{PPh}_{3}\right) \mathrm{I}_{2}-\mathrm{Et}_{3} \mathrm{Al}$ should not proceed by radical polymerization mechanism, and the main product must be produced by a polymerization mechanism different from that with $\mathrm{Et}_{3} \mathrm{Al}$ alone.

The main chain structures of the produced polymers were examined since no highly stereoregular poly(AN) has been obtained thus far. Figure 2 shows the methine carbon region of ${ }^{13} \mathrm{C}$ NMR spectrum of poly(AN) obtained by $\mathrm{CpCo}\left(\mathrm{PPh}_{3}\right) \mathrm{I}_{2}-\mathrm{Et}_{3} \mathrm{Al}$. The highest field peak was assigned to the isotactic triad, though the central and low field peaks corresponded to hetero- and syndiotactic triad, respectively. ${ }^{16}$ The intensity ratio of these three peaks was about $25: 45: 30$, indicating that the poly (AN) has an atactic structure. Due to the $\alpha$-methyl proton of ${ }^{1} \mathrm{H}$ NMR around $1.0 \mathrm{ppm}$ the poly(MMA) produced with $\mathrm{CpCo}\left(\mathrm{PPh}_{3}\right) \mathrm{I}_{2}-\mathrm{Et}_{3} \mathrm{Al}$ possessed a syndiotactic-rich atactic structure (Figure 3). Neither the structure of cobalt complex nor polymerization conditions affected the polymer main-chain structure of either monomer.

Acknowledgment. The authors appreciate the financial support by New Energy and Industrial Technology Development Organization (NEDO) for the project on Technology for Novel High-Functional Materials in Science and Industry Frontier Program, Agency of Indus-

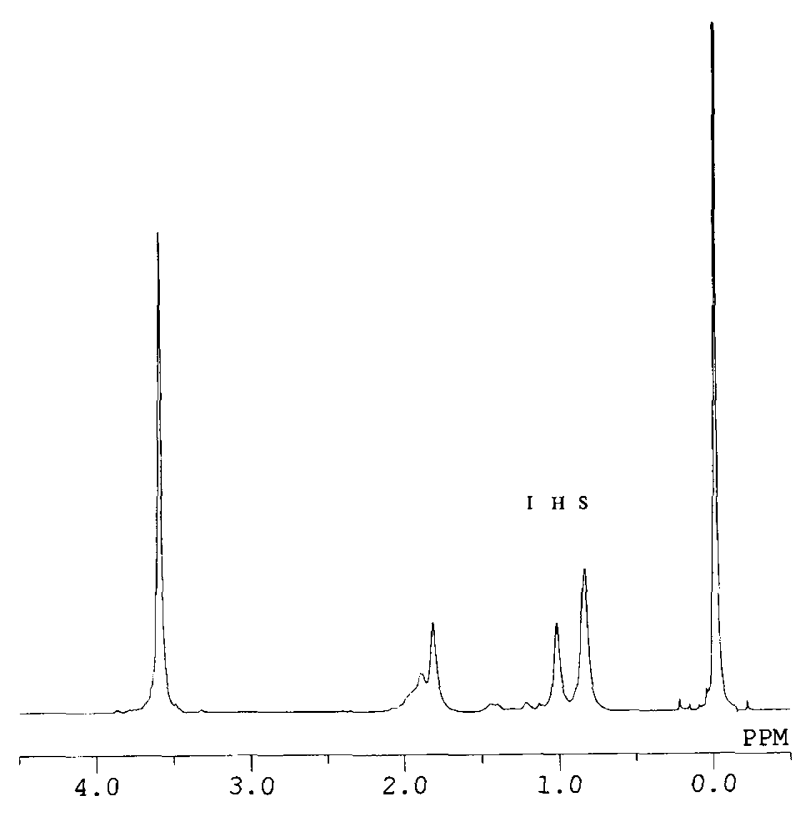

Figure 3. ${ }^{1} \mathrm{H}$ NMR spectrum of poly(MMA) obtained by $\mathrm{CpCo}\left(\mathrm{PPh}_{3}\right) \mathrm{I}_{2}-\mathrm{Et}_{3} \mathrm{Al}$ (measured in $\mathrm{CDCl}_{3}$ ).

trial Science and Technology.

\section{REFERENCES}

1. K. Soga, T. Deng, T. Yano, and T. Shiono, Macromolecules, 27, 7938 (1994).

2. H. Yasuda and E. Ihara, Adv. Polym. Sci., 133, 53 (1997).

3. A. Yamamoto and T. Yamamoto, J. Polym. Sci: Macromolecular Reviews, 13, 161 (1978).

4. J. Hu, G. Qi, and Q. Shen, J. Rare Earths, 13, 144 (1995).

5. L. Jiang, Y. Zhang, and Z. Shen, Eur. Polym. J., 33, 577 (1997).

6. K. Tsuchihara, Y. Suzuki, M. Asai, and K. Soga, Chem. Lett., 891 (1999).

7. K. C. Hultzsch, T. P. Spaniol, and J. Okuda, Angew. Chem. Int. Ed. Engl., 38, 227 (1999).

8. W. Kaminsky, Macromol. Chem. Phys., 197, 3907 (1996).

9. H. H. Brintzinger, D. Fischer, R. Mülhaupt, R. Rieger, and R. M. Waymouth, Angew. Chem. Int. Ed. Engl, 34, 1143 (1995).

10. K. Mashima, Y. Nakayama, and A. Nakamura, Adv. Polym. Sci., 133, 1 (1997).

11. K. Endo, A. Inukai, and T. Otsu, Macromol. Rapid Commun., 15, 893 (1994).

12. H. Yamazaki and N. Hagihara, J. Organometallic Chem., 21, $431(1970)$

13. R. B. King, Inorg. Chem., 5, 82 (1966).

14. M. Brookhart, J. M. DeSimone, B. E. Grant, and M. J. Tanner, Macromolecules, 28, 5378 (1995).

15. M. Sawamoto and M. Kamigaito, Trends Polym. Sci., 4, 317 (1996).

16. Y. Inoue and A. Nishioka, Polym. J., 3, 149 (1972). 